\title{
Cloning, Expression, and Type II Collagenolytic Activity of Matrix Metalloproteinase-13 from Human Osteoarthritic Cartilage
}

\author{
Peter G. Mitchell, Holly A. Magna, Lisa M. Reeves, Lori L. Lopresti-Morrow, Sue A. Yocum, Philip J. Rosner, \\ Kieran F. Geoghegan, and John E. Hambor \\ Central Research Division, Pfizer Inc., Groton, Connecticut 06340
}

\begin{abstract}
Proteolysis of triple-helical collagen is an important step in the progression toward irreversible tissue damage in osteoarthritis. Earlier work on the expression of enzymes in cartilage suggested that collagenase-1 (MMP-1) contributes to the process. Degenerate reverse transcription polymerase chain reaction experiments, Northern blot analysis, and direct immunodetection have now provided evidence that collagenase-3 (MMP-13), an enzyme recently cloned from human breast carcinoma, is expressed by chondrocytes in human osteoarthritic cartilage. Variable levels of MMP-13 mRNA were present in total RNA prepared from six osteoarthritic cartilage samples. Expression of both MMP-13 and MMP-1 in cartilage was significantly induced at both the message and protein levels by interleukin-1 $\alpha$. Recombinant MMP-13 cleaved type II collagen to give characteristic 3/4 and 1/4 fragments; however, MMP-13 turned over type II collagen at least 10 times faster than MMP-1. Experiments with intact type II collagen as well as a synthetic peptide suggested that MMP-13 cleaved type II collagen at the same bond as MMP-1, but this was then followed by a secondary cleavage that removed three amino acids from the 1/4 fragment amino terminus. The expression of MMP-13 in osteoarthritic cartilage and its activity against type II collagen suggest that the enzyme plays a significant role in cartilage collagen degradation, and must consequently form part of a complex target for proposed therapeutic interventions based on collagenase inhibition. (J. Clin. Invest. 1996. 97: 761-768.) Key words: collagen • osteoarthritis • articular • degeneration $\cdot$ joint
\end{abstract}

The amino acid sequence of human type II collagen and its numbering were taken as listed in Swiss-Prot accession P02458 (identified as CA12_HUMAN).

Address correspondence to Dr. P.G. Mitchell, Pfizer Central Research, Eastern Point Road, Groton, CT 06340. Phone: 203-441-5965; FAX: 203-441-5719.

Received for publication 28 September 1995 and accepted in revised form 18 November 1995.

1. Abbreviations used in this paper: APMA, 4-aminophenylmercuric acetate; MALDI-TOF MS, matrix-assisted laser desorption-ionization time-of-flight mass spectrometry; MMP, matrix metalloproteinase; RACE, rapid amplification of cDNA ends; RT-PCR, reverse transcription-PCR; TFA, trifluoroacetic acid.

J. Clin. Invest.

(C) The American Society for Clinical Investigation, Inc.

0021-9738/96/02/0761/08 \$2.00

Volume 97, Number 3, February 1996, 761-768

\section{Introduction}

The vertebrate collagenases are a group of zinc-dependent matrix metalloproteinases (MMPs) ${ }^{1}$ distinguished by their capacity to cleave triple-helical collagen at a single site resulting in fragments corresponding to 75 and $25 \%$ of its initial length $(1,2)$. Until recently, only two such enzymes were known in the human; interstitial collagenase (MMP-1) and neutrophil collagenase (MMP-8). The recent cloning from breast tumor cells of an additional human collagenase (MMP-13) has resolved an anomaly in the interspecies comparison of MMPs (3). Sequence alignments show that MMP-13 is the human homologue of a rat collagenase previously regarded as a divergent homologue of MMP-1. This elucidation of a further human collagenase adds to the complexity of accounting for the enzymatic activities underlying healthy and disease-related processes of collagen catabolism.

Loss of collagen with associated fibrillation of the cartilage is a prominent characteristic of osteoarthritis. In severe disease, the integrity of cartilage can be seriously compromised, with lesions extending to the bone. A positive correlation exists between neutral collagenolytic activity in osteoarthritic cartilage and the severity of lesions (4), but the identity of the enzyme or enzymes responsible remains uncertain. There is evidence that MMP-1 contributes to pathological cartilage degradation, as both mRNA for MMP-1 and the enzyme itself have been detected in tissue from osteoarthritic patients (5-7). The question has remained open as to whether all activity directed toward initial helical type II collagen cleavage, the distinctive function of the true collagenases, has been accounted for in osteoarthritis and other joint diseases.

To search for previously undetected metalloproteinases in cartilage, we have performed degenerate reverse transcription-PCR (RT-PCR) experiments on RNA isolated from human chondrocytes stimulated with IL- $1 \alpha$. This approach yielded a sequence fragment which, on extension to full length, proved to be identical to that of MMP-13. It is shown in this paper that message encoding MMP-13, like that for MMP-1, is expressed at significant but variable levels in human osteoarthritic cartilage. Moreover, MMP-13 message and protein are both substantially upregulated in response to treatment with IL-1 $\alpha$, further indicating a contribution by this enzyme to inflammatory disease processes in joint cartilage.

Recombinant MMP-13 was found to degrade human type II collagen at least 10 -fold faster than MMP-1. Turnover $\left(V_{\max }\right)$ and the enzyme-substrate affinity $\left(K_{\mathrm{M}}\right)$ for human MMP-13 acting on human type II collagen were similar to reported values for rat collagenase (8). Edman sequence analysis of enzyme-treated type II collagen and experiments conducted with a synthetic peptide substrate suggested that MMP-13 makes its initial attack on type II collagen at the peptide bond (Gly ${ }^{906}$ $\mathrm{Leu}^{907}$ ) attacked by MMP-1. Unlike MMP-1, however, MMP-13 
proceeds to affect a secondary cleavage in the $\mathrm{COOH}$-terminal (smaller) collagen fragment, cleaving the peptide bond Gly ${ }^{909}$. Gln ${ }^{910}$ to produce a glutamine $\mathrm{NH}_{2}$ terminus.

\section{Methods}

Materials. The peptide substrate acetyl-RPPGPQGLAGQRGIVGR$\mathrm{NH}_{2}$ was obtained as a product of custom synthesis by American Peptide Co. (Sunnyvale, CA). Human recombinant IL-1 $\alpha$ was purchased from Upstate Biotechnology Inc. (Lake Placid, NY). The probe used in detecting MMP-1 message was a 2.05-kb HindIII/SmaI insert from the pCllase 1 clone obtained from the American Type Culture Collection (Rockville, MD) while the MMP-13 probe was a full-length human cDNA. Human, tissue-specific total RNA was purchased from Clontech Laboratories, Inc. (Palo Alto, CA). Alpha-labeled $\left[{ }^{32} \mathrm{P}\right] \mathrm{dATP}(3,000 \mathrm{Ci} / \mathrm{mmol})$ and $\left.\mathrm{L}-{ }^{35} \mathrm{~S}\right]$ methionine $(1,150 \mathrm{Ci} / \mathrm{mmol})$ were from New England Nuclear (Boston, MA). Protein A-Sepharose CL-4B was obtained from Pharmacia Biotech Inc. (Piscataway, NJ). 4-Aminophenylmercuric acetate (APMA), bacterial collagenase, and pronase were purchased from Sigma Chemical Co. (St. Louis, MO). Polyacrylamide gels were obtained from Novex (San Diego, CA). Neuman and Tytell's serum-free medium was supplied by Gibco Laboratories (Grand Island, NY).

Protein sources. Recombinant human MMP-1 and MMP-13 were purified from the culture medium of $S f 9$ cells infected with recombinant baculovirus. MMP-1 was affinity purified using a monoclonal antibody column using methods essentially as described by Birkedal-Hansen et al. (9). Human MMP-13 was purified using a combination of heparin-agarose and SP-Sepharose Fast Flow columns. Both proteins were $>95 \%$ pure as assessed by Coomassie blue staining of gels. Rat MMP-13 was supplied by Dr. John Jeffrey (Albany Medical College, Albany, NY) while Dr. Robin Poole (Shriners Hospital, Montreal, Canada) provided human fetal type II collagen.

Cartilage organ culture. Human cartilage was obtained from osteoarthritic knee joints at the time of total joint replacement. The cartilage was removed from the underlying bone under aseptic conditions and placed into Neuman and Tytell's serum-free medium containing $20 \mathrm{mM}$ Hepes, pH 7.2, penicillin, streptomycin, amphotericin, and gentamicin.

Human chondrocyte cultures were prepared by sequential digestion of cartilage with trypsin and bacterial collagenase as reported previously (10). Cells were plated at $4 \times 10^{5} \mathrm{cells} / \mathrm{cm}^{2}$ and cultured in DME containing $10 \%$ FBS.

RNA preparation and Northern analysis. Total RNA was prepared from chondrocyte monolayers by lysis in guanidinium isothiocyanate and precipitation with $\mathrm{LiCl}$ as described previously (10). RNA was prepared from cartilage in a similar manner except that the cartilage was first diced into small pieces then digested sequentially with pronase $(4 \mathrm{mg} / \mathrm{ml})$ for $1.5 \mathrm{~h}$ followed by bacterial collagenase $(3 \mathrm{mg} / \mathrm{ml})$ for $1.5 \mathrm{~h}$. The released cells were pelleted and washed with PBS, and RNA was then prepared as for monolayer cultures. Northern blot analysis was carried out using $20 \mu \mathrm{g}$ RNA/lane. Probes were labeled with a random primer kit (Pharmacia Biotech Inc.) and blots were hybridized overnight. After hybridization, the blots were washed several times with the final wash of $0.3 \times \mathrm{SSC} / 0.1 \% \mathrm{SDS}$ at $55^{\circ} \mathrm{C}$. Blots were reprobed after washing for $15 \mathrm{~min}$ in $0.3 \times \mathrm{SSC}$ at $95^{\circ} \mathrm{C}$.

$P C R$ amplification of human chondrocyte RNA. Total RNA was prepared from IL-1-stimulated human cartilage and synthesized into cDNA using Superscript Reverse Transcriptase (GIBCO-BRL, Gaithersburg, MD) and oligo dT as a primer. This cDNA was used for PCR with degenerate oligonucleotides (100 pmol/reaction) corresponding to the highly conserved cysteine switch and zinc binding domains of MMPs (5'-CCCAGRTGTGAAGTKCCWGAYGTKG-3' and 5'-GGAATTCCRTGSCCRARYTCRTG-3', respectively, where $\mathrm{R}=\mathrm{A}+\mathrm{G}, \mathrm{W}=\mathrm{A}+\mathrm{T}, \mathrm{Y}=\mathrm{C}+\mathrm{T}, \mathrm{K}=\mathrm{T}+\mathrm{G}$, and $\mathrm{S}=\mathrm{G}+\mathrm{C})$. PCR was performed in a 9600 GeneAmp PCR thermal cycler (Perkin Elmer, Norwalk, CT) for 30 cycles of denaturation $\left(94^{\circ} \mathrm{C}, 1 \mathrm{~min}\right)$, ramped annealing (starting at $37^{\circ} \mathrm{C}$ for $30 \mathrm{~s}$ and increasing the annealing temperature $1^{\circ} \mathrm{C}$ per cycle and annealing time $1 \mathrm{~s}$ per cycle), and extension $\left(72^{\circ} \mathrm{C}, 1 \mathrm{~min}\right)$. The PCR products were subjected to electrophoresis on a $1 \%$ agarose gel $(1 \times$ TAE), purified using NA-45 membranes (Schleicher and Schuell, Keene, NH), and ligated into pGEM-T (Promega Corp., Madison, WI). DNA from independent clones was isolated and sequenced on an ABI 373 DNA sequencer by the dideoxy chain termination method (11) using fluoresceinated terminators and Taq polymerase. Computer analysis of DNA and protein sequences was performed with the Assembler, Factura (Applied Biosystems, Foster City, CA), and Geneworks (Intelligenetics, Mountain View, CA) software packages.

Cloning of full-length MMP-13 by 5'- and 3' rapid amplification of $c D N A$ ends (RACE). RACE was used to amplify the full-length MMP-13. Total RNA from IL-1-stimulated human cartilage was synthesized into first-strand cDNA using Superscript Reverse Transcriptase and oligo dT. The first-strand cDNA was used to amplify the $3^{\prime}$ end of MMP-13. A sense gene specific primer (5'- ATGACTCAWTCTGAAGTCGAAAAG-3') and Universal Amplification Primer (5'-CUACUACUACUAGGCCACGCGTCGACTAGTAC-3'; GIBCO-BRL) were used for 30 cycles in a Perkin-Elmer 9600 thermal cycler $\left(94^{\circ} \mathrm{C}\right.$ for $30 \mathrm{~s}, 55^{\circ} \mathrm{C}$ for $30 \mathrm{~s}, 72^{\circ} \mathrm{C}$ for $30 \mathrm{~s}$ ). The PCR products were electrophoresed on a $1.0 \%$ agarose gel $(1 \times \mathrm{TAE})$, purified using NA-45 membrane (Schleicher and Schuell), ligated into pGEM-T (Promega Corp.), and transformed into DH5a competent Escherichia coli (GIBCO-BRL). Independent clones were picked, and DNA was sequenced on an $A B I 373$ sequencer by the dideoxy chain termination method (11).

The first-strand cDNA prepared from total RNA from IL-1-stimulated cartilage was oligo-dC-tailed using TdT (terminal deoxynucleotidyl transferase) at $37^{\circ} \mathrm{C}$ for $10 \mathrm{~min}$ (final concentration: $20 \mathrm{mM}$ Tris-Cl, pH 8.4, $50 \mathrm{mM} \mathrm{KCl}, 1.5 \mathrm{mM} \mathrm{MgCl} 2,200 \mu \mathrm{M} \mathrm{dCTP}, 0.4 \mathrm{U} / \mu \mathrm{l}$ TdT). PCR amplification of the dC-tailed cDNA was performed in the same reaction buffer using a gene specific antisense primer (5'-GCCTTTGGAACTACTTGTCCAGG-3') and anchor primer (CUACUACUACUAGGCCACGCGTCGACTAGTACGGGIIGGGIIGGGIIG-3'; GIBCO-BRL). The anchor primer minimizes priming at internal GC rich regions. 35 cycles of PCR were performed in a reaction mixture of $20 \mathrm{mM}$ Tris $\mathrm{Cl}, \mathrm{pH} 8.4,50 \mathrm{mM} \mathrm{KCl}, 5 \mathrm{mM} \mathrm{MgCl}_{2}$, $100 \mathrm{nM}$ gene specific primer, $100 \mathrm{nM}$ anchor primer, $200 \mu \mathrm{M}$ each dATP, dCTP, dGTP, and dTTP, and $0.2 \mathrm{U} / \mu \mathrm{l} \mathrm{Taq}$ polymerase at $94^{\circ} \mathrm{C}$ for $30 \mathrm{~s}$ denaturation, annealing from $37^{\circ} \mathrm{C}+0.5^{\circ} \mathrm{C} /$ cycle $-1 \mathrm{~s} /$ cycle and extension at $72^{\circ} \mathrm{C}$ for $30 \mathrm{~s}$. The PCR products were electrophoresed on a $1.0 \%$ agarose gel $(1 \times \mathrm{TAE})$ and purified on NA-45 membrane (Schleicher and Schuell), ligated into pGEM-T (Promega Corp.), and transformed into DH5a competent E. coli (GIBCO$\mathrm{BRL}$ ). Independent clones were picked and DNA sequenced on ABI 373 sequencer by the dideoxy chain termination method (11).

Antibodies and immunoprecipitations. Antibody to rat MMP-13 was kindly supplied by Dr. John Jeffrey. The antibody to rat MMP-13 had minimal cross-reactivity on western blots with human MMP-1, MMP-2, MMP-3, and MMP-9, but strongly recognized both rat MMP-13 and human MMP-13. Polyclonal antibody to human MMP-1 was prepared by immunizing New Zealand White rabbits with purified MMP-1 (East Acres Biologicals, Southbridge, MA), and had minimal cross-reactivity on Western blots with human MMP-2, MMP-3, MMP-9, MMP-13, and rat MMP-13. Samples of labeled conditioned medium $(0.5 \mathrm{ml})$ were adjusted to $10 \mathrm{mM}$ Tris, $\mathrm{pH} 7.4,0.5 \%$ Triton X-100, $0.1 \%$ SDS, and $0.5 \%$ deoxycholate. $80 \mu$ of protein A-Sepharose CL-4B was then added along with $10 \mu \mathrm{l}$ of antiserum to either MMP-1 or MMP-13, and the samples were placed in a rocking device for overnight incubation at $4^{\circ} \mathrm{C}$. The resulting immunoprecipitates were washed, boiled in reducing sample buffer, and fractionated on $10 \%$ polyacrylamide gels.

Kinetic analyses. Kinetic analyses were performed essentially as described by Welgus et al. (8). Tubes containing type II collagen (4$12 \mu \mathrm{g}$ total) were incubated for $15 \mathrm{~min}$ at $25^{\circ} \mathrm{C}$ with $2.5 \mu \mathrm{g}$ of MMP-1 in Tris buffer ( $50 \mathrm{mM}$ Tris, $\left.10 \mathrm{mM} \mathrm{CaCl}_{2}, 200 \mathrm{mM} \mathrm{NaCl}, \mathrm{pH} 7.2\right)$ in a 
final volume of $50 \mu \mathrm{l}$. After incubation for $15 \mathrm{~min}$ at $25^{\circ} \mathrm{C}$, the reaction was terminated by the addition of $10 \mu \mathrm{l}$ of $6 \times$ reducing sample buffer followed by boiling the samples for $3 \mathrm{~min}$. The samples were then fractionated on $8 \%$ polyacrylamide gels, and the gels were stained with Coomassie blue and destained in water. Relative intensities of the bands corresponding to uncleaved $\alpha \mathrm{I}(\mathrm{II})$ bands and $\mathrm{TC}^{\mathrm{A}}$ were evaluated using a Bio-Rad GS-670 scanning densitometer, and the percentage of total collagen degraded was calculated as $4 / 3\left[\mathrm{TC}^{\mathrm{A}}\right] /$ $\left(4 / 3\left[\mathrm{TC}^{\mathrm{A}}\right]+\alpha\right)$. Reaction velocity was calculated as the number of collagen molecules degraded per molecule of collagenase per hour.

Protein sequencing. $\mathrm{NH}_{2}$-terminal sequence analyses were performed using an Applied Biosystems Model 473A sequencer with an on-board PTH analyzer. The PTH derivative of hydroxyproline was identified by reference to the compilation of retention times for modified PTH-amino acids published by the Association of Biomolecular Resource Facilities (12).

HPLC and mass spectrometry. Action of the collagenases against the synthetic peptide was monitored by HPLC performed on a Hewlett-Packard 1090 system using a Vydac C18 column $(2.1 \times 250$ $\mathrm{mm}$; type 218TP52) running at $0.2 \mathrm{ml} / \mathrm{min}$. Solvents were: A, $0.1 \%$ trifluoroacetic acid (TFA); and B, $0.085 \%$ TFA in $80 \%$ acetonitrile. A gradient of $0-50 \%$ B (i.e., $0-40 \%$ acetonitrile) was run from 1 to 31 min after injection.

Matrix-assisted laser desorption-ionization time-of-flight mass spectrometry (MALDI-TOF MS) was performed on a Voyager II spectrometer (Perseptive Biosystems, Framingham, MA). Steel probe pins were cleaned by sonication in $50 \%$ methanol $/ 0.1 \%$ TFA/ $\mathrm{H}_{2} \mathrm{O}$ for $5 \mathrm{~min}$, then washed with water and vacuum dried. $\alpha$-Cyano4-hydroxycinnamic acid, used as the matrix compound, was obtained as a ready-to-use solution from Hewlett-Packard. Working stock so-

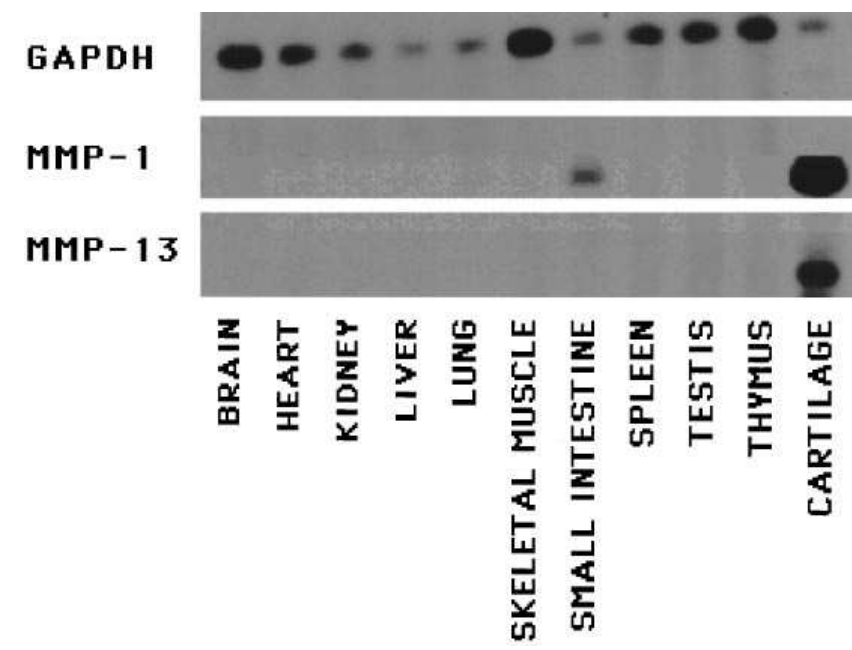

Figure 1. Expression of MMP-1 and MMP-13 in various tissues by RT-PCR. Total RNA from osteoarthritic cartilage and a variety of other tissues was reverse transcribed into cDNA using Superscript Reverse Transcriptase and oligo dT as a primer. The cDNA was amplified by PCR for 30 cycles using primer pairs specific for MMP-1 (forward primer, 5' -ATTTCTCCGCTTTTCAACTT-3'; reverse primer, 5'-ATGCACAGCTTTCCTCCACT-3'), MMP-13 (forward primer, 5'-TGCTGCATTCTCCTTCAGGA-3'; reverse primer, 5'-ATGCATCCAGGGGTCCTGGC-3'), or glyceraldehyde-3-phosphate dehydrogenase (GAPDH; forward primer, 5'-CCACCCATGGCAAATTCCATGGCA-3'; reverse primer, 5' -TCTAGACGGCAGGTCAGGTCCACC-3'; Stratagene, La Jolla, CA).

Digoxigenin-coupled dUTP (Boehringer Mannheim, Indianapolis, IN) was incorporated into the PCR product and semiquantitated by detection with an anti-digoxigenin-peroxidase conjugated antibody and 2,2-azino-di-[3-ethylbenzthiazoline sulfonate]. lutions of the calibrating peptides, $\left[\mathrm{Val}^{4}\right]$ angiotensin III $\left(\mathrm{MH}^{+}=\right.$ 918.1) (5 pmol $/ \mathrm{ml}$ in $0.1 \%$ TFA) and angiotensinogen fragment 1-13 $\left(\mathrm{MH}^{+}=1646.9\right)(20 \mathrm{pmol} / \mathrm{ml}$ in $0.1 \%$ TFA $)$, were stored at $-20^{\circ} \mathrm{C}$ in $5-\mu 1$ aliquots for one time use. These solutions were mixed 1:1 immediately before use and kept on ice. Matrix $(1.0 \mu \mathrm{l})$, analyte $(1.0 \mu \mathrm{l})$, and calibrant mixture $(0.5 \mu \mathrm{l})$, in the order stated, were spotted onto the pin using separate pipette tips. Samples were vacuum dried for 10 min before being analyzed in the spectrometer.

\section{Results}

Degenerate PCR of reverse transcribed RNA isolated from IL-1-stimulated human chondrocytes yielded a fragment from which a full-length cDNA sequence was obtained using $3^{\prime}$ and $5^{\prime}$ RACE. This full-length sequence was identical to that reported for human MMP-13 by Freije et al. (3). Human MMP13 protein was then expressed in insect cells using a baculovirus expression system and purified from the culture medium.

Tissue distribution of the MMP-13 and MMP-1 mRNAs was studied using RT-PCR with RNA isolated from a variety of tissues. MMP-1 mRNA was detected in both the small intestine and cartilage, while MMP-13 mRNA was detected in cartilage only (Fig. 1). Total RNA was then prepared from six specimens of osteoarthritic cartilage obtained at joint replacement and was probed by Northern blotting for evidence of MMP-13 and MMP-1 expression (Fig. 2). MMP-1 mRNA was readily detectable in three samples (Fig. 2, lanes $A, E$, and $F$ ), was detected at very low levels in two (lanes $C$ and $D$ ), and was absent in one (lane $G$ ). When the blot was reprobed for MMP13 mRNA, two transcripts migrating near 3.0 and $2.5 \mathrm{~kb}$ were detected in four (Fig. 2, lanes $C, E, F$, and $G$ ) of the six samples. Multiple MMP-13 transcripts (3.0, 2.5 and $2.0 \mathrm{~kb})$ in hu-

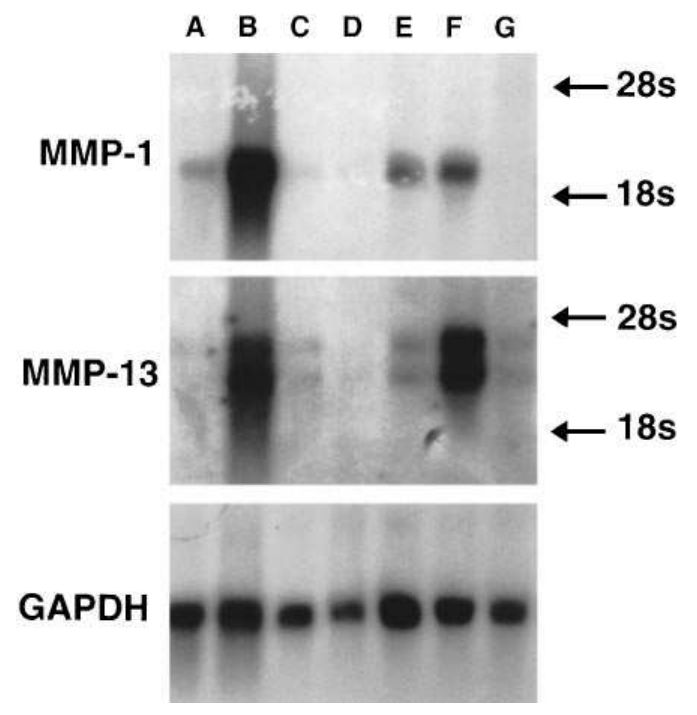

Figure 2. MMP-1 and MMP-13 mRNA expression in human osteoarthritic cartilage. Total RNA was prepared from cartilage obtained from six osteoarthritic knee joints. Northern blot analysis was carried out and the blot was probed with labeled MMP-1 cDNA and then washed and probed with a cDNA for MMP-13 followed by a labeled glyceraldehyde-3-phosphate dehydrogenase (GAPDH) cDNA. Cartilage from donor 1 was split into two aliquots and cultured overnight in serum-free conditions in either the absence (lane $A$ ) or presence (lane $B$ ) of IL- $1 \alpha(5 \mathrm{ng} / \mathrm{ml})$. Lane $C$, donor 2; lane $D$, donor 3; lane $E$, donor 4; lane $F$, donor 5 ; lane $G$, donor 6 . 


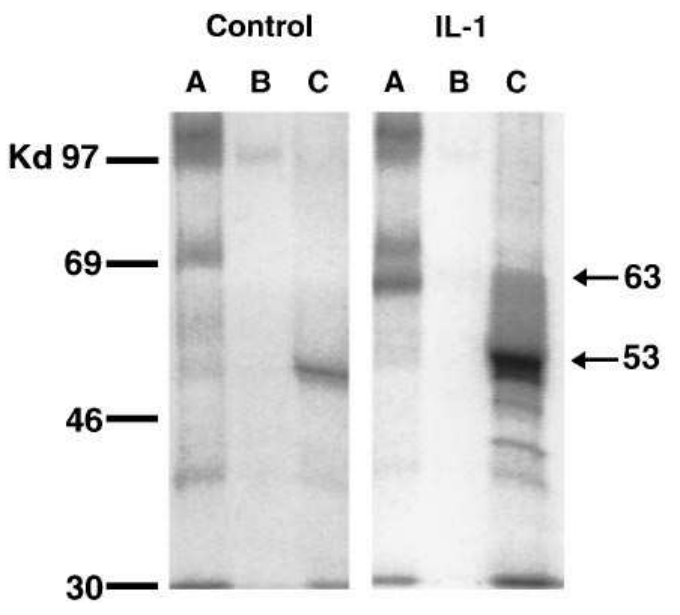

Figure 3. Immunoprecipitation of MMP-1 and MMP-13 from human osteoarthritic cartilage. Cartilage from donor 1 was split into two equal aliquots ( 2 grams each) and incubated in methionine-deficient medium in either the absence (Control) or presence of IL-1 $\alpha$ ( $5 \mathrm{ng}$ / $\mathrm{ml})$ for $36 \mathrm{~h} .\left[{ }^{35} \mathrm{~S}\right]$ Methionine $(100 \mu \mathrm{Ci} / \mathrm{ml})$ was present throughout the culture period. 1-ml samples of both the control and IL- $1 \alpha$-conditioned media were then immunoprecipitated sequentially with polyclonal antibody to rat collagenase (lane $A$ ), rat collagenase again (lane $B$ ), and human MMP-1 (lane $C$ ). Samples were fractionated on a $10 \%$ polyacrylamide gel and labeled proteins were detected by fluorography.

man breast carcinoma reported by Freije et al. (3) were due to differences in lengths of the $3^{\prime}$ untranslated region as a result of alternative polyadenylation. Of interest, relative mRNA levels varied significantly between different samples, with one donor expressing MMP-1 mRNA but not MMP-13 mRNA (Fig. 2, lane $A$ ) and one donor expressing MMP-13 mRNA but not MMP-1 mRNA (lane $G$ ). We were unable to obtain samples of normal human cartilage, but in experiments with monolayers of normal porcine chondrocytes no mRNA expression for either MMP-1 or MMP-13 was detected until stimulation with IL-1 (data not shown).

We next investigated whether expression of MMP-13 was inducible by a cytokine, as had been reported previously for MMP-1. When osteoarthritic cartilage (donor 1) was treated overnight with IL-1 $\alpha$, both MMP-1 and MMP-13 mRNAs were significantly upregulated (Fig. 2, lane B). Parallel cultures using cartilage from the same donor were also used to investigate the effect of IL- $1 \alpha$ on secretion of MMP- 1 and MMP13 protein. Cartilage from donor 1 was incubated for $36 \mathrm{~h}$ with IL- $1 \alpha$ in the presence of $\left[{ }^{35} \mathrm{~S}\right]$ methionine. The resulting labeled conditioned medium was then probed with immunoprecipitating antibodies to either MMP-1 or MMP-13. To demonstrate that the proteins detected were immunologically distinct, sequential immunoprecipitations were performed from the same media samples (Fig. 3). When antibody to rat MMP-13 was added to the medium first, a protein running at $63 \mathrm{kD}$ was specifically immunoprecipitated from the IL- $1 \alpha$-treated sample but not from the untreated sample (compare Fig. 3, control lane $A$ and IL-1 lane $A$ ). The observed molecular mass of 63 $\mathrm{kD}$ is higher than that predicted from the amino acid sequence of MMP-13, but is likely due to glycosylation as reported for MMP-1 (13). The same samples of media were then treated a second time with antibody to rat MMP-13 and no further protein was immunoprecipitated (Fig. 3, control lane $B$ and IL-1

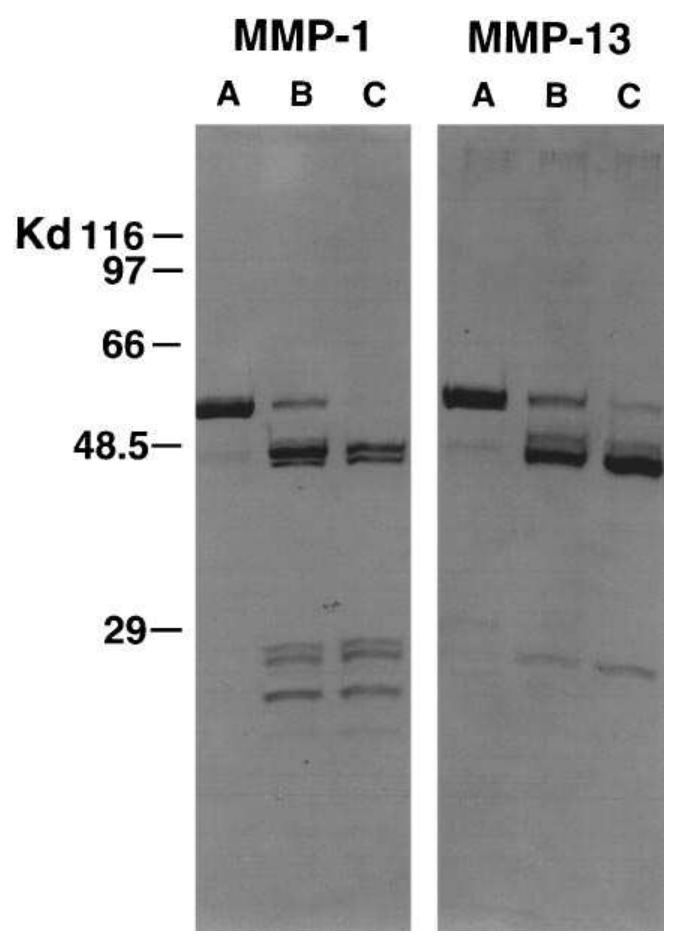

Figure 4. APMA activation of MMP-1 and MMP-13. 1 mM APMA was added to $50 \mu \mathrm{l}$ of recombinant MMP-1 $(500 \mu \mathrm{g} / \mathrm{ml})$ and incubated at $37^{\circ} \mathrm{C}$. Similarly, 2 mM APMA was added to MMP-13 (150 $\mu \mathrm{g} / \mathrm{ml}$ ) in buffer containing $600 \mathrm{mM} \mathrm{NaCl}$ and incubated at $37^{\circ} \mathrm{C}$. After 0,30 , and $60 \mathrm{~min}$, aliquots were removed from both samples, added to reducing sample buffer and boiled. The samples were then separated on a $10 \%$ gel and silver stained.

lane $B$ ). When antibody to human MMP-1 was then added to the samples, a major band running at $53 \mathrm{kD}$, consistent with the molecular mass of human pro-MMP-1 (13), was detected in SDS-PAGE analysis of the resulting immunoprecipitate (Fig. 3, control lane $C$ and IL-1 lane $C$ ). Small amounts of the protein were detected in the unstimulated samples but it was clear that the level of protein had increased significantly in response to IL- $1 \alpha$.

Study of the collagenolytic activity of MMP-13 required a procedure for activation of the recombinant proenzyme. Treatment of recombinant 56-kD pro-MMP-13 with $2 \mathrm{mM}$

\section{MMP-1 \\ ${ }^{82}$ E T L K V M K QP R C G VPDVA Q F V ${ }^{*} L^{*} T E G N P R W E$ \\ MMP-13 \\ ${ }^{86}{ }^{3}$ T L V M KKPR C G VPDVGEY ${ }^{+} N \vee F P R T L K W S$}

Figure 5. $\mathrm{NH}_{2}$ termini of APMA-activated MMP-1 and MMP-13. MMP-1 $(500 \mu \mathrm{g} / \mathrm{ml})$ was incubated with $1 \mathrm{mM}$ APMA for $30 \mathrm{~min}$ at $37^{\circ} \mathrm{C}$. MMP-13 $(150 \mu \mathrm{g} / \mathrm{ml})$ was incubated with $2 \mathrm{mM}$ APMA for 60 min at $37^{\circ} \mathrm{C}$. Samples of each protein were separated on a $10 \%$ polyacrylamide gel, blotted onto PVDF membrane, and stained. The 47-kD MMP-13 band as well as the 47- and 45-kD MMP-1 bands were excised and $\mathrm{NH}_{2}$-terminally sequenced. Conserved amino acids are shown in bold. ${ }^{*} \mathrm{NH}_{2}$-terminal amino acids after APMA activation of MMP-1. ${ }^{\wedge} \mathrm{NH}_{2}$ terminus of MMP-1 after stromelysin activation (15). ${ }^{+} \mathrm{NH}_{2}$-terminus of MMP-13 after APMA activation. 


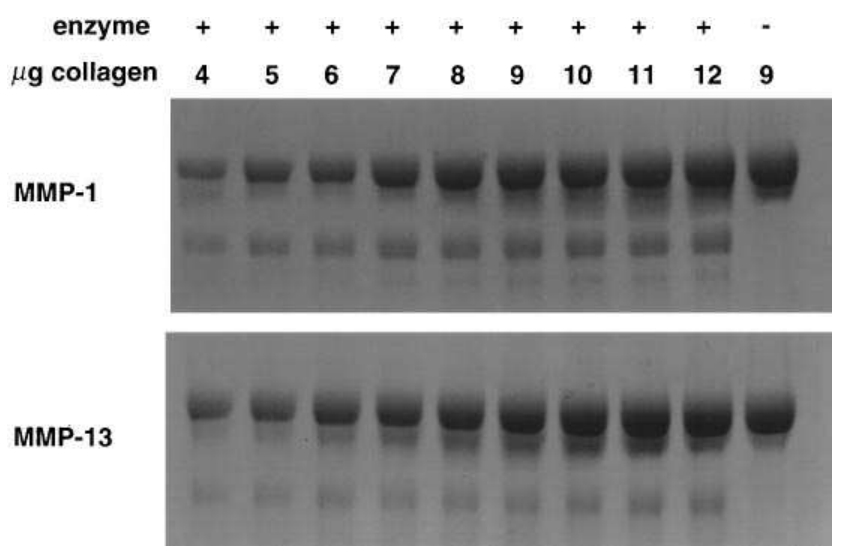

Figure 6. MMP-1 and MMP-13 degradation of type II collagen. Activated MMP-1 $(2.5 \mu \mathrm{g})$ was added to tubes containing increasing amounts of human type II collagen $(4,5,6,7,8,9,10,11$, and $12 \mu \mathrm{g})$ and buffer ( $50 \mathrm{mM}$ Tris, $\left.\mathrm{pH} 7.5,10 \mathrm{mM} \mathrm{CaCl}_{2}, 100 \mathrm{mM} \mathrm{NaCl}\right)$ in a total volume of $50 \mu \mathrm{l}$. The tubes were incubated at $25^{\circ} \mathrm{C}$ for $15 \mathrm{~min}$, then reducing sample was added and the samples were boiled. The samples were then separated on an $8 \%$ polyacrylamide gel, stained with Coomassie blue, and destained in water. MMP-13 was assayed in a similar manner except $0.3 \mu \mathrm{g}$ of enzyme was used. One tube containing $9 \mu \mathrm{g}$ of collagen but no added enzyme was run in the first lane.

APMA for $1 \mathrm{~h}$ at $37^{\circ} \mathrm{C}$ in $0.6 \mathrm{M} \mathrm{NaCl}$ resulted in its near-quantitative conversion to a major $47-\mathrm{kD}$ product in a manner that closely resembled the APMA-dependent activation of proMMP-1 (Fig. 4). To obtain quantitative conversion of MMP-13 to its active species over this time period it was necessary to use $2 \mathrm{mM}$ APMA as compared with $1 \mathrm{mM}$ APMA to obtain quantitative conversion of MMP-1 to its major active species. $\mathrm{NH}_{2}$-terminal sequence analysis of the respective APMA-activated forms of both enzymes was performed using PVDF-blotted protein samples and generated the $\mathrm{NH}_{2}$ termini listed in Fig. 5. As reported previously, the upper band resulting from APMA activation of MMP-1 had an $\mathrm{NH}_{2}$ terminus beginning at $\mathrm{Leu}^{84}$ (numbering from the initiating methionine) while the lower $45-\mathrm{kD}$ band had a mixture of $\mathrm{Val}^{101}$ and $\mathrm{Leu}^{102} \mathrm{NH}_{2}$ termini $(14,15)$. APMA-dependent activation of MMP-13 pro-
Table I. Kinetic Parameters for Human MMP-1, Human $M M P-13$, and Rat Collagenase Calculated from the Lineweaver-Burk Plots in Fig. 6

\begin{tabular}{llcc}
\hline & $K_{\mathrm{M}}$ & $k_{\text {cat }}$ & $k_{\text {cat }} / K_{\mathrm{M}}$ \\
\hline & $\mu M$ & $h^{-1}$ & $\mu M^{-1} h^{-1}$ \\
Human MMP-13* & 2 & 23 & \\
Rat collagenase (8) & 0.9 & 14.2 & 11.5 \\
Human MMP-1* & 1.0 & 2 & 15.7 \\
Human MMP-1 (16) & 2.1 & 1.0 & 2 \\
& & & 0.5
\end{tabular}

$k_{\text {cat }}$ is expressed as molecules of type II collagen cleaved $/$ molecule of collagenase/hour; * Data from this work.

duced enzyme with a homogeneous $\mathrm{NH}_{2}$ terminus beginning at $\mathrm{Tyr}^{104}$.

Kinetic analyses of the degradation of type II collagen by MMP-1 and MMP-13 were performed as described by Welgus et al. (8). Samples containing increasing amounts of type II collagen and constant amounts of activated enzyme (MMP-1 or MMP-13) were incubated at $25^{\circ} \mathrm{C}$ for $15 \mathrm{~min}$, and then fractionated by electrophoresis on $8 \%$ polyacrylamide gels. The gels were stained with Coomassie blue (Fig. 6), bands were integrated using a laser densitometer, and the percentage of substrate degraded was calculated. Almost 10-fold more MMP-1 $(2.5 \mu \mathrm{g})$ than MMP-13 $(0.3 \mu \mathrm{g})$ was required to run assays over the same period of time (15 min) and obtain similar, low levels of substrate degradation. Lineweaver-Burk plots were constructed from the velocity data (Fig. 7), and values of $K_{\mathrm{M}}$ and $k_{\text {cat }}$ were extracted (Table I). MMP- 1 exhibited a $K_{\mathrm{M}}$ of $1 \mu \mathrm{M}$ and a $k_{\text {cat }}$ of 2 molecules of collagen degraded $/ \mathrm{molecule}$ of collagenase/h, similar to values reported previously (16). For human MMP-13, the calculated values of $K_{\mathrm{M}}(2 \mu \mathrm{M})$ and $k_{\text {cat }}(23$ molecules of collagen degraded $/$ molecule of collagenase $/ \mathrm{h}$ ) are very close to those established for rat MMP-13 (8). Thus, although the enzymes exhibited similar values of $K_{\mathrm{M}}$ for type II collagen, the maximum rate of type II collagen hydrolysis catalyzed by MMP-13 was 10 times more rapid than that for MMP-1 under comparable conditions.

MMP-1 cleaves type II collagen at the peptide bond Gly ${ }^{906}$ $\mathrm{Leu}^{907}(1)$, and the resulting products migrate on polyacryl-
MMP-13

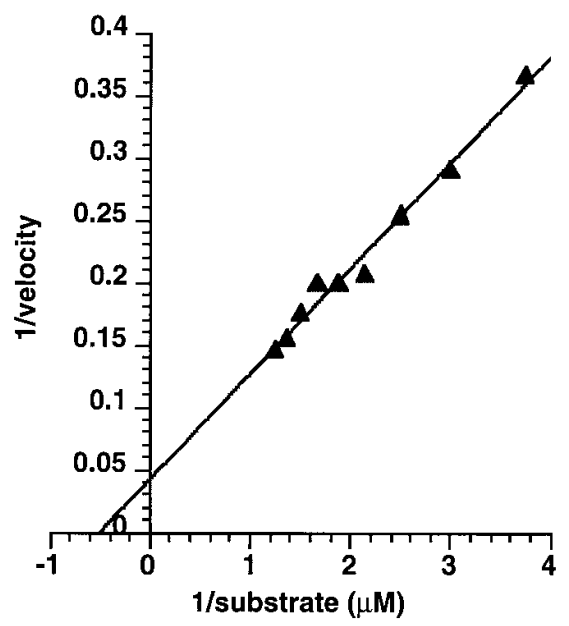

MMP-1

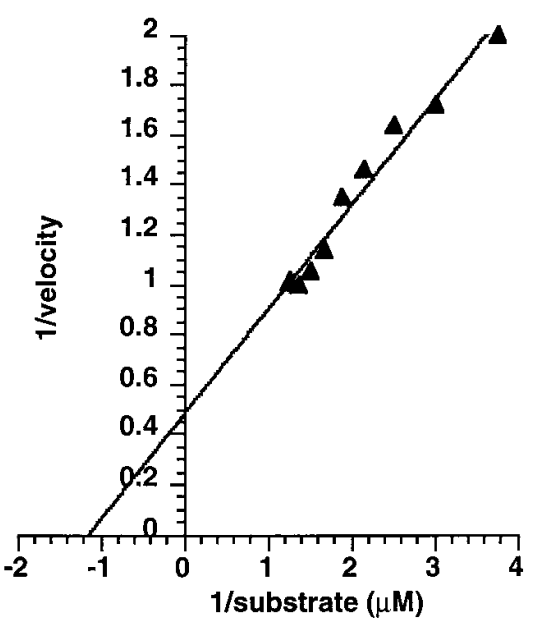

Figure 7. Lineweaver-Burk plots for MMP-1 and MMP-13 degradation of human type II collagen. Using the gels from Fig. 6, the percent degradation at each collagen concentration was determined by integration of the staining intensity of both the undegraded chains and the $\mathrm{TC}^{\mathrm{A}}$ product for each condition. Enzyme velocity $(\mathrm{v}=\mathrm{mol}-$ ecules of collagen degraded/molecule of enzyme) was calculated and $1 /[$ substrate] vs. $1 / \mathrm{v}$ was then plotted. $K_{\mathrm{M}}$ and $k_{\text {cat }}$ values were calculated from the intercepts on the $x$ - and $y$-axes, respectively. 
Table II. Major $\mathrm{NH}_{2}$-Terminal Sequence Signals Obtained from 1/4 Fragment of Type II Collagen Digested with MMP-1 or $M M P-13$

\begin{tabular}{cccccc}
\hline & \multicolumn{2}{c}{ MMP-1 } & & \multicolumn{2}{c}{ MMP-13 } \\
\cline { 2 - 3 } \cline { 5 - 6 } Cycle & PTH-amino acid & pmol* $^{*}$ & & PTH-amino acid & pmol* $^{*}$ \\
\hline 1 & Leu & 3.0 & & Gln & 5.0 \\
2 & Ala & 5.1 & & Arg & 6.9 \\
3 & Gly & 5.0 & & Gly & 6.5 \\
4 & Gln & 2.7 & & Ile & 6.7 \\
5 & Arg & 2.9 & & Val & 6.2 \\
6 & Gly & 4.7 & & Gly & 5.6 \\
7 & Ile & 2.3 & & Leu & 4.9 \\
8 & Val & 4.3 & Hydroxyproline & ND \\
9 & Gly & 4.1 & & Gly & 3.9 \\
10 & Leu & 3.4 & & Gln & 2.4 \\
11 & Hydroxyproline & ND & Arg & 2.8 \\
12 & Gly & 2.7 & Gly & 3.0 \\
& & & & \\
\hline
\end{tabular}

* All picomole values reported are background corrected. No other signal detected was present at a level $>10 \%$ of the principal signal given in the table. $N D$, not determined.

amide gels in a pattern that reflects their correspondence with $3 /$ 4 and 1/4, respectively, of the initial mass of the collagen molecule. MMP-13-treated type II collagen gave a similar pair of products, and the site at which cleavage occurred was investigated by $\mathrm{NH}_{2}$-terminal sequence analysis of the smaller fragment isolated from an electroblot to PVDF. In an experiment showing almost complete cleavage of the starting material into $3 / 4$ and $1 / 4$ bands by MMP-13, the predominant $\mathrm{NH}_{2}$ terminus on the $1 / 4$ fragment was $\operatorname{Gln}^{910}$ (Table II) with a small proportion of product having an $\mathrm{NH}_{2}$ terminus of $\mathrm{Leu}^{907}$ (i.e., the $\mathrm{NH}_{2}$ terminus produced by the action of MMP-1). Similar data were obtained when tissue-derived rat MMP-13 was used instead of recombinant human MMP-13 (not shown). Cleavage of type II collagen with MMP-1 produced a predominant $\mathrm{NH}_{2}$ terminus corresponding to $\mathrm{Leu}^{907}$ although a very weak secondary sequence consistent with an $\mathrm{NH}_{2}$ terminus of $\mathrm{Gln}^{910}$ was discernible.

It appeared that this observed $\mathrm{NH}_{2}$ terminus would likely have arisen either by a predominant primary cleavage at Gly ${ }^{909}-\mathrm{Gln}^{910}$ or by a primary cleavage at Gly ${ }^{906}-\mathrm{Leu}^{907}$ followed by a secondary cleavage at Gly ${ }^{909}-\mathrm{Gln}^{910}$. In an effort to discriminate further between these possibilities, the separate activities of MMP-1 and MMP-13 were studied against a 17-

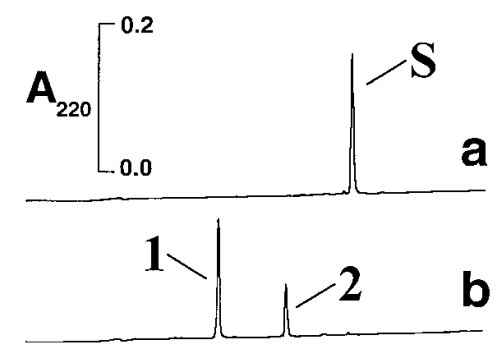

Figure 8. Activities of MMP-1 and MMP-13 against a synthetic peptide substrate analyzed by HPLC. Peaks are indicated by a letter or number on the first occasion that they occur in the descending series of chromatograms $a-d$, and were identified by MALDI-TOF MS (see

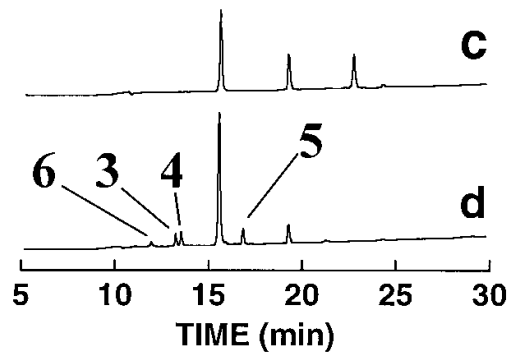
for experimental details. (a) Control incubation of the peptide Ac-RPPGPQGLAGQ RGIVGR-NH ${ }_{2}$ in the absence of any enzyme. (b) Peptide $(50 \mu \mathrm{M})$ was incubated for $11 \mathrm{~h}$ in the presence of 0.25

$\mu \mathrm{M}$ MMP-1. (c) Peptide $(50 \mu \mathrm{M})$ was incubated for $30 \mathrm{~min}$ in the presence of $0.025 \mu \mathrm{M}$ MMP-13. (d) Peptide $(50 \mu \mathrm{M})$ was incubated for $3 \mathrm{~h}$ in the presence of $0.25 \mu \mathrm{M}$ MMP-13.

residue peptide substrate covering their sites of action in type II collagen. This peptide had the sequence acetyl-RPPGPQGLAGQRGIVGR-NH ${ }_{2}$, which matched residues 901-915 of human type II collagen with the addition of an arginyl residue at each terminus to promote solubility. The peptide (50 $\mu \mathrm{M}$ ) was separately incubated with $0.025,0.05$, and $0.25 \mu \mathrm{M}$ concentrations of MMP-1 and with the same series of concentrations of MMP-13. Reactions were allowed to proceed at room temperature (about $22^{\circ} \mathrm{C}$ ) and periodically analyzed by HPLC to follow their progress (Fig. 8). Peaks corresponding to cleavage products of the peptide substrate were collected by hand and characterized by MALDI-TOF MS (Table III). Extended treatment of the peptide with MMP-1 led to significant cleavage only at the bond corresponding to $\mathrm{Gly}^{906}-\mathrm{Leu}^{907}$ of type II collagen (Fig. 8 b). Recombinant human MMP-13 initially cleaved the peptide at the same bond (Fig. $8 c$ ), but subsequently (and more slowly) cleaved one of the two resulting fragments at sites corresponding to Gly ${ }^{909}-\mathrm{Gln}^{910}$ and Gly ${ }^{912}$ $\mathrm{Ile}^{913}$ (Fig. $8 d$ ). This result indicated that the $\mathrm{Gln}^{910} \mathrm{NH}_{2}$ terminus observed after MMP-13-catalyzed cleavage of type II col-

Table III. Mass Spectrometric Analysis of a Collagenase Peptide Substrate and the Products of Its Cleavage by MMP-1 and $M M P-13$

\begin{tabular}{lclr}
\hline HPLC peak* & MH $^{+}$observed & \multicolumn{1}{c}{ Identified as } & MH $^{+}$theoretical \\
\hline $\mathrm{S}$ & 1757.8 & Ac-RPPGPQGLAGQRGIVGR-NH & 1758.0 \\
1 & 750.9 & Ac-RPPGPQG & 750.8 \\
2 & 1026.5 & LAGQRGIVGR-NH & 1026.2 \\
3 & 601.8 & LAGQRG & 601.7 \\
4 & 443.6 & IVGR-NH & 443.5 \\
5 & 784.7 & QRGIVGR-NH & 784.9 \\
6 & 259.9 & LAG & 260.3 \\
\hline
\end{tabular}

\footnotetext{
* Peaks are identified as shown in Fig. 8.
} 
lagen is most likely the result of a secondary cleavage, and that the initial cleavage occurs at the same site as that attacked by MMP-1.

\section{Discussion}

Using a PCR approach based on the highly conserved cysteine switch and active site domains in MMPs, we have identified MMP-13 in IL- $1 \alpha$-stimulated human chondrocytes. The sequence of chondrocyte MMP-13 was confirmed to be identical to that reported for MMP-13 isolated by Freije et al. from a human breast carcinoma cDNA (3). Tissue distribution studies by RT PCR showed that of the tissues investigated expression of MMP-13 was limited to cartilage. MMP-1 expression was also detected in cartilage but interestingly, we were also able to detect low expression of MMP-1 in mRNA from small intestine. It is unknown what the significance of MMP-1 expression is in this tissue. In other experiments, IL- $1 \alpha$ induced expression of MMP-1 but not MMP-13 in both human fibroblasts and human gingival cells (data not shown). Thus, the expression of MMP-13 appears to be regulated in a very tissue-specific manner.

The RT-PCR data on expression of MMP-13 in cartilage were confirmed using Northern blot analysis. Cartilage from three out of six osteoarthritic knee joints expressed readily detectable levels of both MMP-1 and MMP-13 mRNAs as indicated by Northern blot analysis. However, the relative levels of message for the two enzymes were not constant between different samples. For example, cartilage from donor 1 was expressing MMP-1 but not MMP-13, while cartilage from donor 6 was expressing MMP-13 but not MMP-1. This observation suggested that the mRNA levels for these two enzymes can be independently regulated. The level of expression between different patients was quite variable; however, osteoarthritis is likely a multifactorial process with a number of factors such as degree of inflammation, medication, and the mechanical environment of the joint possibly playing a role in both the amount and spectrum of MMP expression.

As has been observed previously for MMP-1 in chondrocytes $(10,17)$, treating cartilage with a cytokine substantially upregulated the expression of mRNA for both MMP-1 and MMP-13. Antibodies to both MMP-1 and MMP-13 were able to specifically immunoprecipitate proteins, consistent with their respective identities, from the cartilage conditioned medium. The MMP-13 protein immunoprecipitated had a higher molecular weight than might be expected from the amino acid sequence; however, this was likely due to posttranslational glycosylation of the protein since MMP-13 has three potential $\mathrm{N}$-linked glycosylation sites (asparagines 117, 124, and 152). Observations at the level of mRNA and secreted protein were consistent. MMP-13 mRNA was not detected in the unstimulated cartilage and no MMP-13 protein was immunoprecipitated from its conditioned medium. In contrast, the unstimulated cartilage did contain low levels of MMP-1 mRNA and a small amount of MMP-1 protein was immunoprecipitated from its medium. mRNA and protein for both MMP-1 and MMP-13 were substantially upregulated after IL- $1 \alpha$ treatment. In sum, these data demonstrated that both MMP-1 and MMP13 can be expressed by osteoarthritic cartilage, a result that suggests that both enzymes may contribute to the degradation of cartilage collagen. Thus, it is likely that the collagenolytic activity observed previously in osteoarthritic cartilage (4) is due to a mixture of at least these two enzymes.
As is typical of other MMPs, the proenzyme form of human MMP-13 was activated by incubation with APMA. Activation was associated with a reduction in molecular mass from 56 to $47 \mathrm{kD}$. The primary amino acid sequence of MMP-13 contains three potential N-linked glycosylation sites at asparagines 117, 124, and 152 and the difference in molecular mass between the recombinant MMP-13 (56 kD) and the MMP-13 immunoprecipitated from cartilage conditioned medium (64 $\mathrm{kD}$ ) is most likely due to more extensive glycosylation of the natural enzyme. Under the conditions used in this work, activation of pro-MMP-13 led to a mature enzyme with a homogeneous $\mathrm{NH}_{2}$ terminus beginning at $\mathrm{Tyr}^{104}$. APMA activation of MMP-1 produced a mixture of $\mathrm{NH}_{2}$ termini beginning at $\mathrm{Leu}^{84}, \mathrm{Val}^{101}$, and $\mathrm{Leu}^{102}$, similar to the result reported previously $(14,15)$. Alignment of sequences conserved between MMP-1 and MMP-13 showed that Tyr ${ }^{104}$ of MMP-13 fell at the same relative position as $\mathrm{Phe}^{100}$ of MMP-1. The $\mathrm{Phe}^{100} \mathrm{NH}_{2}$ terminus of MMP-1 is produced by treatment with stromelysin and produces an active MMP-1 species with the highest known specific activity (15). Modeling studies using the crystal structure of MMP-1 have suggested that the $\mathrm{Phe}^{100} \mathrm{NH}_{2}$ terminus of MMP-1 stabilizes the active site via a salt bridge between the protonated $\mathrm{NH}_{2}$-terminal amino group and the side chain of a highly conserved aspartic acid residue (18). It is possible that the $\mathrm{Tyr}^{104} \mathrm{NH}_{2}$-terminus of MMP-13 functions in an analogous manner.

Sequence comparisons indicate that human MMP-13 is the human homologue of the rat collagenase from uterine tissue (19). It was generally presumed that the rat and mouse collagenases were the rodent equivalent of human MMP-1, even though the rat and human enzymes were divergent in both sequence $(20,21)$ and activity (8). A further major difficulty with this concept was the divergent catalytic efficiencies exhibited by the human and rodent enzymes against different collagens. Human MMP-1 displays wide variations in catalytic efficiency, with $k_{\text {cat }}$ varying between $565 \mathrm{~h}^{-1}$ for human type III collagen and $1.0 \mathrm{~h}^{-1}$ for type II collagen (16). In contrast, rat collagenase exhibits relatively constant $k_{\text {cat }}$ for human collagens with reported values of 20.2 and $14.2 \mathrm{~h}^{-1}$ for type III and type II, respectively (8). Although both rat collagenase and human MMP-1 displayed similar $K_{\mathrm{M}}$ for type II collagen (0.9 and 2.1 $\mu \mathrm{M}$, respectively), the $k_{\text {cat }}$ for rat collagenase was $>10$-fold higher than that for human MMP-1. Indeed, the poor catalytic efficiency of human MMP-1 for type II collagen prompted the suggestion some time ago that there might exist other, more specific human type II collagenases (16).

In our work, kinetic values determined for the action of recombinant human MMP-1 on type II collagen were similar to values previously reported for collagenase purified from normal human skin fibroblasts (16). The $K_{\mathrm{M}}$ and $k_{\text {cat }}$ values for recombinant human MMP-13 were very similar to those reported previously for rat collagenase purified from the resorbing postpartum uterus (8). The data add similarity at the level of function to the high degree of sequence homology between rat collagenase and human MMP-13 and confirm that these enzymes have much higher specific activity against type II collagen than does MMP-1.

Although it appears that MMP-1 and MMP-13 both cleave type II collagen initially at the same site, MMP-13 affects a secondary cleavage to produce a 1/4-size collagen fragment with an $\mathrm{NH}_{2}$ terminus three amino acids removed from the primary cleavage site. The ability of MMP-13 to produce at least one 
further cleavage correlates with the observation that rat MMP13 cleaves denatured type I collagen much faster and at a wider variety of sites than does MMP-1 (22). The distinct $\mathrm{NH}_{2}$ termini generated by prolonged action of the two enzymes may provide a diagnostic tool for dissecting their relative importance in degrading the collagen of cartilage.

The present work has demonstrated expression of MMP-13 in human osteoarthritic cartilage and shown that MMP-13 has significant type II collagen degrading activity. The relative contributions of MMP-1 and MMP-13 to human osteoarthritis remain unknown and will depend on a number of variables including their relative expression levels, their degree and type of activation, and their relative activity against other cartilage macromolecules. In spite of these uncertainties, our data suggest that future therapeutic intervention aimed at restricting damage to cartilage collagen will need to include inhibition of MMP-13 as well as MMP-1.

\section{Acknowledgments}

The authors gratefully acknowledge the support of Michael Fogliano and Sue Williams in the sequencing laboratory at Pfizer Central Research. We would also like to thank Dr. Jung and his surgical team at Lawrence and Memorial Hospital in New London for providing cartilage specimens. Useful discussions with Dr. John Jeffrey of Albany Medical College are also gratefully acknowledged.

\section{References}

1. Miller, E.J., E.D. Harris, E. Chung, J.E. Finch, P.A. McCroskery, and W.T. Butler. 1976. Cleavage of type II and III collagens with mammalian collagenase: site of cleavage and primary structure at the $\mathrm{NH}_{2}$-terminal portion of the smaller fragment released from both collagens. Biochemistry. 15:787-792.

2. Fietzek, P.P., and K. Kuhn. 1976. The primary structure of collagen. Int. Rev. Connect. Tissue Res. 7:1-60.

3. Freije, J.M.P., I. Diez-Itza, M. Balbib, L.M. Sanchez, R. Blasco, J. Tolivia, and C. Lopez-Otin. 1994. Molecular cloning and expression of collagenase-3, a novel human matrix metalloproteinase produced by breast carcinomas. J. Biol. Chem. 269:16766-16773.

4. Pelletier, J.-P., J. Martel-Pelletier, D.S. Howell, L.G. Ghandur-Mnaymneh, J.E. Enis, and J.F. Woessner, Jr. 1983. Collagenase and collagenolytic activity in human osteoarthritic cartilage. Arthritis Rheum. 26:63-68.

5. Wolfe, G.C., K.L. MacNaul, F.F. Beuchel, J. McDonnell, L.A. Hoerrner, M.W. Lark, V.L. Moore, and N.I. Hutchinson. 1993. Differential in vivo expres- sion of collagenase messenger RNA in synovium and cartilage. Arthritis Rheum. 36:1540-1547.

6. Lohmander, L.S., L.A. Hoerrner, and M.W. Lark. 1993. Metalloproteinases, tissue inhibitor, and proteoglycan fragments in knee synovial fluid in human osteoarthritis. Arthritis Rheum. 36:181-189.

7. Clark, I.M., L.K. Powell, S. Ramsey, B.L. Hazelman, and T.E. Cawston. 1993. The measurement of collagenase, tissue inhibitor of metalloproteinases (TIMP), and collagenase-TIMP complex in synovial fluids from patients with osteoarthritis and rheumatoid arthritis. Arthritis Rheum. 36:372-379.

8. Welgus, H.G., D.K. Kobayashi, and J.J. Jeffrey. 1983. The collagen substrate specificity of rat uterus collagenase. J. Biol. Chem. 258:14162-14165.

9. Birkedal-Hansen, B., W.G.I. Moore, R.E. Taylor, A.S. Bhown, and H. Birkedal-Hansen. 1988. Monoclonal antibodies to human fibroblast procollagenase. Inhibition of enzymatic activity, affinity purification of the enzyme, and evidence for clustering of epitopes in the $\mathrm{NH}_{2}$-terminal end of the activated enzyme. Biochemistry. 27:6751-6758.

10. Mitchell, P.G., and H.S. Cheung. 1991. Tumor necrosis alpha and epidermal growth factor regulation of collagenase and stromelysin in adult porcine articular chondrocytes. J. Cell. Physiol. 149:132-140.

11. Sanger, F., S. Nicklen, and A.R. Coulson. 1977. DNA sequencing with chain-terminating inhibitors. Proc. Natl. Acad. Sci. USA. 74:5463-5467.

12. Crankshaw, M.W., and G.A. Grant. 1993. Identification of modified PTH-amino acids in protein sequence analysis. M.W. Crankshaw and G.A. Grant, editors. Association of Biomolecular Resource Facilities.

13. Wilhelm, S.M., A.Z. Eisen, M. Teter, S.D. Clark, A. Kronberger, and G. Goldberg. 1986. Human fibroblast collagenase: glycosylation and tissue-specific levels of enzyme synthesis. Proc. Natl. Acad. Sci. USA. 83:3756-3760.

14. Grant, G.A., A.Z. Eisen, B.L. Marmer, W.T. Roswit, and G.I. Goldberg. 1987. The activation of human skin fibroblast collagenase. J. Biol. Chem. 262:5886-5889.

15. Suzuki, K., J.J. Enghild, T. Morodomi, G. Salvesen, and H. Nagase. 1990. Mechanisms of activation of tissue procollagenase by matrix metalloproteinase 3 (stromelysin). Biochemistry. 29:10261-10270.

16. Welgus, H.G., J.J. Jeffrey, and A.Z. Eisen. 1981. The collagen substrate specificity of human skin fibroblast collagenase. J. Biol. Chem. 256:9511-9515.

17. Gowen, M., D.D. Wood, E.J. Ihrie, J.E. Meats, and R.G.G. Russell. 1984. Stimulation by human interleukin 1 of cartilage breakdown and production of collagenase by human chondrocytes but not by human osteoblasts in vitro. Biochim. Biophys. Acta. 797:186-193.

18. Reinemer, P., F. Grams, R. Huber, T. Kleine, S. Schierer, M. Piper, H. Tschesche, and W. Bode. 1994. Structural implications for the role of the N terminus in the "superactivation" of collagenases. FEBS Lett. 338:227-233.

19. Roswit, W.T., J. Halme, and J.J. Jeffrey. 1983. Purification and properties of rat uterine procollagenase. Arch. Biochem. Biophys. 225:285-295.

20. Quinn, C.O., D.K. Scott, C.E. Brinckerhoff, L.M. Matrisian, J.J. Jeffrey, and N.C. Partridge. 1990. Rat collagenase. Cloning, amino acid sequence comparison, and parathyroid hormone regulation in osteoblastic cells. J. Biol. Chem. 265:22342-22347.

21. Henriet, P., G.G. Rousseau, and Y. Esckhout. 1992. Cloning and sequencing of mouse collagenase cDNA. Divergence of mouse and rat collagenases from other mammalian collagenases. FEBS Lett. 310:175-178.

22. Welgus, H.G., G.A. Grant, J.C. Sacchettini, W.T. Roswit, and J.J. Jeffrey. 1985. The gelatinolytic activity of rat uterus collagenase. J. Biol. Chem. 260:13601-13606. 